\title{
Countermeasure Research on the Development of Trade in Tourism Service in Hainan under the Background of One belt One Road
}

\author{
Xiaoli Yang ${ }^{1}$ \\ ${ }^{1}$ School of International Trade and Foreign Languages Haikou University of Economics, Haikou, China
}

\begin{abstract}
With the proposal of the Belt and Road Initiative, Hainan has witnessed a great development opportunity. This article analyzes the importance of Hainan in the Belt and Road Initiative from the perspectives of history, location and culture. Based on the prop position of tourism industry in Hainan's economy, it puts forward that trade in tourism service should be considered as an important joint point for the construction of "One Belt, One Road". Countermeasures and suggestions for the development of trade in tourism service in Hainan are put forward combined with the strategic background of "One Belt, One Road".
\end{abstract}

\section{Hainan's role in the "maritime Silk Road" initiative}

Before the emergence of the land silk road, there was a maritime silk road. According to historical records, in the ancient maritime silk road, Hainan, which is in a leading position in the South China Sea, could not only replenish supplies for ships coming and going, but also had frequent trade with neighboring countries based on its own advantages, and became a key and transit station for trade and cargo transportation between mainland and countries along the ancient silk road. "21st Century Maritime Silk Road" Initiative was proposed by President Xi Jinping in 2013 when he visited ASEAN member states, suggesting that China will strengthen cooperation with the countries along the belt. In the contact between China and the countries along the "21st Century Maritime Silk Road", Hainan has unique advantages:

First of all, Hainan is close to the Pearl River Delta, which is economically developed in China. It is also near the Southeast Asia, which is the most active in the Asia Pacific Economic Circle. Good location conditions will make Hainan a bridge between the countries in Southeast Asia and mainland China, as well as a transit station of the maritime silk road. Secondly, the cooperation between Hainan and Southeast Asian countries has good policy advantages, especially since the establishment of China ASEAN Free Trade Area, the flow of people, logistics and capital between Hainan and ASEAN member countries has been improved unprecedentedly, and trade exchanges have been strengthened constantly. Finally, there are more than 2 million overseas Chinese of Hainan nationality in Southeast Asia, and more than 200 overseas Chinese organizations in Southeast Asia have maintained friendly relations with Hainan for a long time. Among them, some overseas Chinese of Hainan nationality have great influence in Southeast Asia, they are active in the government, chamber of commerce and academic circles, and have rich personal resources, which also laid a humanistic foundation for Hainan's participation in the "21st Century Silk Road".

\section{The prop position of tourism service trade in Hainan economy}

In recent years, Hainan has attracted a large number of Chinese and foreign tourists due to its special natural and cultural tourism resources, and the total tourism income has been increasing continuously, as shown in the following table:

Table1. Development of trade in tourism service in Hainan Province from 2008 to 2019

\begin{tabular}{|c|c|c|c|c|}
\hline year & $\begin{array}{c}\text { Total tourism } \\
\text { income } \\
(\mathbf{1 0 0} \text { million) }\end{array}$ & $\begin{array}{c}\text { Inbound } \\
\text { tourism income } \\
(\mathbf{1 0 0 m i l l i o n})\end{array}$ & $\begin{array}{c}\text { GDP } \\
(\mathbf{1 0 0} \\
\text { million) }\end{array}$ & $\begin{array}{c}\text { Contribution of } \\
\text { tourism income } \\
\text { to GDP } \\
(\%)\end{array}$ \\
\hline 2008 & 192.33 & 27.32 & 1459.23 & 13.18 \\
\hline 2009 & 211.72 & 18.9 & 1646.60 & 12.85 \\
\hline 2010 & 257.63 & 22.02 & 2052.12 & 12.55 \\
\hline 2011 & 324.04 & 24.57 & 2515.29 & 12.88 \\
\hline 2012 & 379.12 & 21.75 & 2855.26 & 13.28 \\
\hline 2013 & 428.56 & 20.09 & 3146.46 & 13.62 \\
\hline 2014 & 484.98 & 16.33 & 3500.70 & 14.47 \\
\hline 2015 & 572.49 & 15.29 & 3702.80 & 15.46 \\
\hline 2016 & 669.62 & 23.25 & 4044.51 & 16.56 \\
\hline 2017 & 811.00 & 45.98 & 4462.54 & 18.17 \\
\hline \multicolumn{2}{|c|}{ Data source: National Economic and Social Development Bulletin of } \\
\hline
\end{tabular}

Hainan

It can be seen from the above table that the total tourism income of Hainan Province shows a rising trend from US $\$ 19.233$ billion in 2008 to US $\$ 81.100$ billion in 2017 , with an average annual growth rate of $32.16 \%$; the 
inbound tourism income in 2008 was 2.732 billion yuan, which declined to 1.89 billion yuan in 2009 due to the global financial crisis. From 2010 to 2011, Hainan's inbound tourism revenue increased from 1.89 billion yuan in 2009 to 2.457 billion yuan in 2011. The global economy slump had a negative impact on Hainan's trade in tourism service. After 2012, the inbound tourism income declined, and then continued to rise. The proportion of tourism industry in GDP of Hainan Province is growing, from $13.18 \%$ in 2008 to $18.17 \%$ in 2018 . Tourism has become a backbone industry in Hainan economy.

\section{Significance of developing trade in Hainan's tourism service under the background of one belt, one road.}

Hainan Province should play an active role as a transit station in the strategy of "21st Century Maritime Silk Road", and become a tourist destination for various countries in the "Silk Road Economic Belt" with its unique popularity. On the contrary, the development of tourism service trade will also promote the optimization of Hainan's trade structure.

\subsection{Promoting the Optimization of Trade Structure}

In 2015, the total amount of foreign trade in Hainan Province was 86.862 billion yuan, obviously lower than that of other provinces, and the import and export scale was relatively small. Among them, the amount of service trade accounted for only about $15 \%$ of the total trade volume, which did not suit with Hainan's status as a "a big province of service". Further adjusting and optimizing the foreign trade structure is the primary task for Hainan's foreign trade development. Under the background of One Belt, One Road, the development of Hainan's tourism service trade will continue to expand the scale of Hainan's foreign trade, increase its proportion in the whole trade structure, reduce the proportion of high-energy consumption and low value-added products in foreign trade, optimize the structure of foreign trade commodities and promote the development of Hainan's foreign trade.

\subsection{Reducing the Degree of Trade Dependence}

At present, ASEAN, the United States, Japan, Hong Kong and other places are the main export markets for Hainan. The degree of dependence on these countries and regions is high. "One Belt, One Road" strategy is consistent with the needs of common development for the countries along the route, and is an important opportunity for the countries along the border to participate in international division of labor and international trade by taking advantage of comparative advantages. The cooperation and development between Hainan and the countries along One belt and One Road will help to alleviate the degree of high market concentration, reduce Hainan's degree of dependence on the US and Japan. It is conducive to dispersing market risk.

\subsection{Opening Wider to the Outside World}

"One Belt, One Road" initiative has provided a new platform for China's reform and opening up, and has also brought new opportunities for opening up and economic development for Hainan. Hainan is located in the southernmost part of China with beautiful nature environment. Its unique location and resource advantages determine its special status in the "One Belt, One Road" strategy. Hainan, located in the line of " 21 st Century Marinetime Silk Road", should give a full play to its location advantage as a key node to the Pan South China Economic Cooperation Circle. It will further promote cooperation in Hainan or even the cooperation between China and the Indo -Pacific Regions, and enhance the level of opening up to the outside world and help build the "One Belt and One Rroad". Tourism industry is a backbone industry in Hainan's economy. Hainan will continue to extend the degree of opening for tourism industry and promote the further integration of Hainan and the world through the development of tourism service trade.

\section{Countermeasures and Suggestions on the Development of Trade in Tourism Service in Hainan under the Background of One belt One Road.}

Under the background of One Belt, One Road, Hainan should actively explore the countermeasures for the development of tourism service trade and enhance the competitive advantage of tourism service trade.

\subsection{Improving the Quality of Tourism Workers}

On the one hand, tourism departments should formulate short-term training plans for tourism workers, and regularly carry out knowledge and skills training related to tourism, so that tourism workers can have a basic understanding of the customs and culture of different countries, especially the countries along the "21st Century Maritime Silk Road". They can also be familiar with relevant terms and regulations to improve the comprehensive quality of tourism workers and enhance service level of tourism in Hainan. On the other hand, investment in education and scientific research should be increased by the government. Major of tourism service trade should be set up in vocational colleges and universities, to cultivate a group of high-quality tourism management talents with international management concept and familiar with international tourism service rules.

\subsection{Promoting Supply-side Reform of Tourism Industry}

In recent years, although the total tourism income of Hainan province continues to increase, the problems of tourism industry are prominent, such as poor quality of tourism workers, simple tourism products, repeated construction of low-level tourism projects, backward 
promotion mode of tourism products, and so on. These problems on the supply side of tourism industry are bound to affect the healthy development of tourism industry. The supply side reform of tourism industry is not only a reflection of the development of tourism industry in Hainan province, but also the focus of economic reform in Hainan province. Only by reforming the supply side of tourism industry can we continuously improve the level of tourism service and enhance the competitiveness of Hainan tourism industry.

\subsection{Promoting Interconnection and Intercommunication}

Under the background of One Belt, One Road, Hainan should communicate with other provinces and countries, and strive to build up a network of interconnection and intercommunication for the whole region, and establish a trans-regional silk road covering sea, land and air. First of all, Hainan should further strengthen close cooperation with major airlines, increase air routes and tour charter services to countries along the "Silk Road Economic Belt", so as to build a convenient air bridge for tourism exchange and cooperation. Secondly, Hainan should coordinate with the countries along the "21 st Century Maritime Silk Road" to open cruise tourism routes to Southeast Asia and even further countries, providing maritime channels for tourism exchanges and cooperation. Finally, Hainan should complete the construction of sea-crossing bridge as soon as possible, promote the connection of transportation between Hainan and mainland, and realize more convenient flow of people and logistics.

\subsection{Innovating the Supply Mode of Tourism Products}

The application of computer information technology in tourism industry should be strengthened and the development of tourism e-commerce (OTA) should be promoted. The development of OTA can accumulate a lot of tourism data information in the process of promoting the development of tourism service trade, which is the premise of big data technology applied in tourism industry. On the one hand, the processing and analysis of a large number of tourism data can make the manufacturers of tourism products fully understand the market demand and design and provide demand-oriented tourism products. On the other hand, the classification and processing of tourism data can make the promotion and marketing of tourism products more accurate and improve the efficiency of tourism product promotion and marketing.

\subsection{Strengthening Publicity, Promotion and Mutual Aid}

The development of tourism service trade is inseparable from the publicity and promotion of tourism products. Hainan should positively seek the promotion and cooperation of tourism products with the countries along "One Belt and One Road" (especially in Central Asia, Russia and the Middle East).
The publicity resources of the other countries and modern information technology are used to enhance the popularity of Hainan International Tourism Island in the international market. For example, to improve Hainan's tourism popularity, to broaden channels of selling tourism products and to promote the development of Hainan by setting up special columns and pages introducing Hainan in mainstream media of countries along One belt and One Road, actively participating in international tourism exhibitions and exhibitions and promoting tourism products with the help of tourism information service platforms of countries along the line.

\subsection{Improving the Level of Tourism Investment}

Tourism is a capital and resource driven industry. The reduction of investment will hinder the development of tourism service trade in Hainan. Therefore, Hainan should actively take measures to expand tourism investment. With the support of the central government, Hainan has issued a series of preferential policies for investment, including preferential policies for investment and tax relief. Hainan should actively make use of preferential investment policies, adhere to the implementation of preferential policies, and promote the development of tourism investment. Meanwhile, Hainan should further develop the market of tourism service, actively communicate with countries along one belt, one road, and explore mutually beneficial preferential policies of investment.

\subsection{Establishing Dispute Processing Mechanism between the Investment Subject and the Government}

Under the strategy of One Belt, One Road, a large number of enterprises will become the main subjects of investment, construction and operation, and there will be more cross-regional investment and transnational investment. Because the "One Belt, One Road" involves 64 countries along the route, the change of political situation, economic policies and industrial policies in the countries along the route may bring disputes about the claim for investment losses between the investment subjects and the government concerned. Hainan should call on the Chinese government to actively communicate and consult with countries along the line and explore the mechanism of dispute settlement under the "One Belt, One Road" projects between investors and government to ensure the safety of investment so as to improve the level of tourism investment in Hainan.

\subsection{Seeking a Supervision Mechanism of Tourism Service Trade}

we should give a full play to all kinds of forces and adopt the supervision mode combining the government, the media and the people in the development of Hainan's tourism industry. First of all, departments of government in Hainan should formulate and perfect the existing tourism service rules and regulations to realize the 
docking of tourism service legislation and international rules, and play a guiding role in the development of tourism industry on the basis of learning and understanding the rules of service trade. Secondly, the media should make a true reflection and value guidance on the problems existing in the tourism industry, and play the role of public supervision.

Finally, we should make full use of the public, such as hiring social supervisors who can come from all walks of life. They can supervise effectively and supplement supervision of the government and the media through open and secret investigations on tourist attractions and related services.

\subsection{Innovating the Management Mechanism of Tourism Service Trade}

At present, Hainan Provincial Department of Commerce is the administrative organ of Hainan province's service trade, but the Tourism Commission is the administrative organ of tourism industry. Tourism service trade belongs to the category of service trade, but it can not be separated from the supervision of tourism industry, which leads to the unclear responsibilities between departments and the situation of mutually buck-passing responsibilities when problems arise. In the context of One Belt, One Road, Hainan needs to establish a horizontal linkage management mechanism to develop tourism service trade. The government should establish a linkage mechanism with tourism administrative departments as the main subjects, including industry and commerce department, sanitary department, quality inspection department, public security department, pricing department, consumer associations and other departments to participate in the linkage mechanism, clarify the responsibilities of various administrative departments in the service industry, and set up a joint law enforcement team to crack down on illegal tourism business activities, and effectively supervise activities of tourism service trade.

\section{References}

1. Jingyi Feng, "Building Hainan into a bridgehead of the '21st century Maritime Silk Road',' J. New Oriental. January 2015.

2. Feng, Gao, "From ancient Silk Road to one belt, one road construction”, J. Northern Economy. April,2015.

3. Yanhai,Yang, "An analysis of enhancing the international competitiveness of Hainan tourism service trade," J. Jiangsu Technology Information. October, 2013.

4. Xiang, Cao, "An empirical study on the international competitiveness of Hainan tourism service trade and its influencing factors", J. Tourism Research. June, 2014.

5. Changbo. Jing, and Jia. Guo, "Hainan's third opportunity," N. Hainan Daily, February, 2015.

6. Jinggang, Shan, "Hainan in One belt, one road, interconnection over sea, land and air," N. Hainan Daily, April, 2015.
7. Run, Wang, "It's time to broaden the international tourism market”, N. Hainan Daily, April, 2015.

8. Xiang, Zhang, "Study on the influencing factors of tourism economic growth in Hainan Province", D. Hainan University. 2012.

9. Fengyign,Yuan,"Analysis on Hainan Tourism Development”, D.Tianjinn University, 2011.

10. Qiuxiu, Cao, "One Belt, One Road - new opportunities for tourism in Hainan", J.Subject planning. February, 2015.

11. Xiangying, Wang, "Opportunities and challenges of Hainan tourism service trade under the background of international cooperation", J. Industry and technology Forum. January, 2011.

12. Jiangzheng, Yin, "Research on Hainan tourism marketing strategy based on the construction of international tourism island", J. New Oriental . April, 2010.

13. Qingling,Peng, "Carrying out the 'one belt, one road' Hainan responsibility in the tourist special zone". N. Hainan Daily. March, 2015. 